\title{
Muscle biopsy features in critical ill patients with 2009 influenza A (H1N1) virus infection
}

\author{
Alterações da biópsia muscular em pacientes gravemente acometidos pela infecção \\ por vírus influenza A (H1N1) 2009 \\ Paulo José Lorenzoni, Cláudia Suemi Kamoi Kay, Rosana Herminia Scola, Hipólito Carraro Júnior, \\ Lineu Cesar Werneck
}

\begin{abstract}
Higher serum creatine kinase (CK) levels in critically ill patients with a confirmed 2009 influenza A (H1N1) infection suggests a possible relationship between the H1N1 virus and muscle tissue. However, there have been no reports with an emphasis on muscle biopsies for patients infected with the H1N1 virus. The objective of this study was to investigate the histological characteristics of the muscle biopsies from critically ill patients with confirmed 2009 H1N1 infections. A series of ten patients with confirmed 2009 H1 N1 infection, who presented increased serum CK levels, was analyzed. Histological study found small histochemical alterations in muscles fibers (mainly in NADH, SDH, COX, myophosphorylase, adenylate deaminase and PAS stains), and no histological changes were compatible with inflammatory myopathy. Although our critically ill patients had elevated CK levels, they exhibited few histological/histochemical abnormalities in their muscle biopsy samples; however, those alterations could be consistent with metabolic dysfunction associated with influenza H1N1 infection.
\end{abstract}

Key words: Influenza A virus, H1N1 subtype, creatine kinase, muscle biopsy.

\section{RESUMO}

Os elevados níveis séricos da creatina quinase (CK) em pacientes gravemente acometidos pela infecção por influenza A (H1N1) 2009 sugerem uma possível relação entre infecção pelo vírus H1N1 e alterações do tecido muscular. No entanto, não existem relatos com ênfase nas alterações histológicas encontradas no músculo dos pacientes infectados pelo vírus H1 N1. O objetivo deste estudo foi investigar as características histológicas, em biópsia muscular, de pacientes gravemente acometidos pela infecção por vírus H1N1 2009. Foi analisada uma série de dez pacientes com infecção confirmada por vírus H1N1, que apresentavam nível sérico elevado de CK. O estudo histológico evidenciou pequenas alterações histoquímicas nas fibras musculares (mais evidentes nas colorações por NADH, SDH, COX, miofosforilase, adenilato deaminase e PAS) mas sem alterações histológicas compatíveis com miopatia inflamatória. Embora nossos pacientes mostrassem níveis séricos elevados de CK, foram poucas as alterações histológicas e histoquímicas encontradas em suas biópsias musculares. Contudo, essas alterações podem ser consistentes com uma disfunção metabólica da fibra muscular associada à infecção pelo H1N1.

Palavras-Chave: vírus da Influenza A subtipo H1N1, creatina quinase, biópsia muscular.

In April 2009, a novel swine-origin influenza A (H1N1) virus causing pneumonia and respiratory failure was reported in Mexico and North America ${ }^{1,2}$. Certain baseline characteristics of H1N1 infection were associated with increased mortality, including higher creatine kinase (CK) serum levels. In one report on hospitalized cases of $\mathrm{H} 1 \mathrm{~N} 1$ in Mexico, increased CK serum levels were detected in $62 \%$ of patients ${ }^{1}$. In addition, CK was moderately elevated in the first week of illness in $\mathrm{H} 1 \mathrm{~N} 1$ patients in Canada ${ }^{3}$.

Higher CK levels have been previously associated with seasonal influenza, but the outcome of this complication was worse in critically ill patients infected with the 2009 influenza
A (H1N1) virus because higher CK levels increased the likelihood of death after 28 days ${ }^{4}$.

Other countries presented similar cases of H1N1 infection associated with increased CK levels, suggesting that there is a possible relationship between influenza A (H1N1) virus and muscles. However, to our knowledge, the histopathological aspects of muscle from $\mathrm{H} 1 \mathrm{~N} 1$ patients have not been described.

In this study, we analyzed the muscle biopsy features in critically ill Brazilian patients with confirmed 2009 influenza A (H1N1) infections. These patients underwent a muscle biopsy because of the increased CK levels.

Neuromuscular Disorders Service, Neurology Division, Internal Medicine Department, Hospital de Clínicas, Universidade Federal do Paraná (UFPR), Curitiba PR, Brazil. Correspondence: Lineu Cesar Werneck; Serviço de Doenças Neuromusculares, Hospital de Clínicas da UFPR; Rua General Carneiro 181 / $3^{\circ}$ andar; 80060-900 Curitiba PR - Brasil; E-mail:werneck@hc.ufpr.br Conflict of interest: There is no conflict of interest to declare.

Received 24 November 2011; Received in final form 28 December 2011; Accepted 04 January 2012 


\section{METHODS}

Ten patients were selected through a retrospective analysis of 57 patients who required intensive care unit (ICU) admission due to possible H1N1 infection in July and August 2009 using the following criteria: (1) respiratory failure due to H1N1 infection; (2) severe illness that required ICU admission, ventilator support and a neuraminidase inhibitor (oseltamivir started at hospitalization); (3) H1N1 infection confirmed by RT-PCR analysis in bronchial aspirate samples; (4) increased serum CK (>1,000 U/L) levels upon ICU admission; and (5) a muscle biopsy performed.

The disease time of progression was considered as the time between the initial symptoms and death. Other relevant data, including age, gender and the course of the disease, were collected.

Serum CK levels were measured from ICU admission until the patient died (normal level, $<168 \mathrm{U} / \mathrm{L}$ ).

The muscle biopsies were performed on the quadriceps, gastrocnemius or major pectoral muscles. The muscle biopsies were frozen in liquid nitrogen. Fresh frozen cryostat sections were stained using histology (HE-trichrome, oil red O, PAS, cresyl violet and sirius red) and histochemistry (ATPase, NADH, esterase, myophosphorylase, acid phosphatase, alkaline phosphatase, succinate dehydrogenase, cytochrome-C oxidase and adenylate deaminase) according to standard procedures ${ }^{5}$.

\section{RESULTS}

The sample population consisted of ten patients (four male and six female) who were 20 to 57 years old, with mean age of $37.6 \pm 11.51$ years (Table). All of the patients died in an ICU, and the time of progression of the disease from initial symptoms to death varied from 5 to 18 days, with a mean time of $12 \pm 3.62$ days (Table).

Comorbidities were found in five patients (Table). The comorbidities included: alcoholic cirrhosis (case 1), asthma (case 2), systemic lupus erythematosus (case 3), pregnancy (case 5) and chronic obstructive pulmonary disease (case 8).

Serum CK was elevated when the patients were admitted to the ICU (mean level, 3,744.4 $\pm 5,544.14 \mathrm{U} / \mathrm{L}$; median level, 1,966.5 U/L; range, 1,003 to 19,254 U/L). Fig 1 displays the range of serum CK levels from ICU admission to death.

The most common abnormalities found with the hematoxylin-eosin and modified Gomori trichrome stains were necrosis (4), variability of the diameter of muscular fibers (9), dispersed atrophic round fibers (8) and dispersed atrophic angulated fibers (3). In the NADH-tetrazolium reductase stain, atrophic angulated fibers (1), focal failure in fibers (6) and focal increase NBT granules (2) were found. For the ATPase reaction, type 1 fiber atrophy (1), type 2 fiber atrophy (8) and type 1 fiber predominance (2) were observed. In the nonspecific esterase reaction, atrophic angulated fibers (2) were detected. The acid phosphatase reaction revealed focal increase in fibers (2), and the alkaline phosphatase reaction uncovered interstitial increase (1). Oil red $\mathrm{O}$ revealed a mild increase in some fibers (1) and deficiency in scored fibers (1). In PAS, there was a deficiency in scored fibers (4). After the succinate dehydrogenase reaction, subsarcolemmal accumulation (3) and focal deficiency in fibers (3) were revealed. For the cytochrome C-oxidase reaction, subsarcolemmal accumulation (3) and focal deficiency in fibers (3) were uncovered. In the deaminase adenylate reaction, deficiencies in scored fibers (2) were found. Finally, after the myophosphorylase, deficiencies in scored fibers (5) were detected.

The Table shows the range of the abnormalities found in muscle biopsies. Fig 2 displays histological and histochemical abnormalities in muscle biopsy.

\section{DISCUSSION}

Myositis has been sporadically reported as a complication of both influenza A virus and influenza B virus infections ${ }^{6}$. Rarely, this myositis presents severe muscle damage that results in myoglobinuria and acute renal failure ${ }^{6}$. However, during the 2009 influenza A (H1N1) virus pandemic, muscle complications, including reports of increased CK levels, were described in children and adults. The higher CK levels found in our cases strongly suggest that there was a relationship between the influenza A (H1N1) virus and muscle in critically ill patients.

The pathogenesis of influenza-associated myopathy is poorly understood. Agyeman et al. reviewed the literature on the connections between influenza and muscle and found that some specimens of muscle had no abnormalities or unspecific changes $^{6}$. Thus, some authors have suggested that the term myopathy should be used instead of myositis. Our cases displayed no histological changes that were compatible with inflammatory myopathy, which reinforces the idea that neither invasive direct actions of the virus in muscle fibers nor an immune-mediated process provides a complete explanation for muscular involvement in critically ill patients with 2009 influenza A (H1N1) infections. Myopathy is ultimately a better term than myositis because the majority of muscle biopsies from these cases do not show infiltration by inflammatory cells ${ }^{6}$. Therefore, uncertainty remains as to whether the myopathy is caused by a direct viral action or by immune-mediated mechanisms.

Another hypothesis for the pathogenesis of influenzaassociated myopathy considers the possibility that H1N1 infection is a systemic dysfunction that causes metabolic abnormalities; this possibility is suggested by the link between acute respiratory distress syndrome and multiple organ dysfunction syndrome ${ }^{7}$. Our histological study found small histochemical alterations in muscles fibers (from NADH, SDH, COX, myophosphorylase, adenylate deaminase and PAS 
Table. Clinical and histological characteristics in ten critical ill patients with 2009 Influenza A (H1N1) infection.

\begin{tabular}{|c|c|c|c|c|c|c|c|c|c|c|}
\hline Case & 1 & 2 & 3 & 4 & 5 & 6 & 7 & 8 & 9 & 10 \\
\hline Age, years & 39 & 50 & 28 & 29 & 20 & 39 & 27 & 57 & 44 & 43 \\
\hline Gender & M & $\mathrm{F}$ & $\mathrm{F}$ & F & F & M & $\mathrm{F}$ & M & M & $\mathrm{F}$ \\
\hline Time of progression, days* & 5 & 18 & 11 & 12 & 13 & 12 & 11 & 10 & 11 & 17 \\
\hline Comorbidity & + & + & + & - & + & - & - & + & - & - \\
\hline \multicolumn{11}{|l|}{ Histological findings } \\
\hline Site of muscle biopsy & Q & G & Q & $Q$ & G & $Q$ & $Q$ & G & G & $P$ \\
\hline \multicolumn{11}{|l|}{ HE and modified Gomori trichrome } \\
\hline Necrosis & - & + & - & - & - & + & - & + & - & + \\
\hline Variability of muscular fibers diameter & ++ & + & +++ & + & - & + & + & + & ++ & ++ \\
\hline Atrophic rounded fibers dispersed & + & + & +++ & + & - & + & + & - & + & + \\
\hline Atrophic angulated fibers dispersed & - & - & - & - & - & + & - & + & - & + \\
\hline \multicolumn{11}{|l|}{$\mathrm{NADH}$ - tetrazolium reductase } \\
\hline Atrophic angulated fibers & - & - & - & - & - & - & - & + & - & - \\
\hline Focal failure into fibers & + & ++ & - & - & + & ++ & + & - & ++ & - \\
\hline Focal increase NBT granules & - & - & - & - & +++ & - & + & - & - & - \\
\hline \multicolumn{11}{|l|}{ ATPase (pH 9.4, 4.6 and 4.3) } \\
\hline Type 1 fiber atrophy & - & + & - & - & - & - & - & - & - & - \\
\hline Type 2 fiber atrophy & + & + & ++ & + & - & + & + & - & + & + \\
\hline Type 1 fiber predominance & - & + & - & - & - & - & - & + & - & - \\
\hline \multicolumn{11}{|l|}{ Nonspecific esterase } \\
\hline Atrophic angulated fibers & - & - & - & - & - & ++ & - & + & - & - \\
\hline \multicolumn{11}{|l|}{ Acid phosphatase } \\
\hline Focal increased into fibers & - & + & +++ & - & - & - & - & - & - & - \\
\hline \multicolumn{11}{|l|}{ Alkaline phosphatase } \\
\hline Interstitial increase & - & - & + & - & - & - & - & - & - & - \\
\hline \multicolumn{11}{|l|}{ Oil red 0} \\
\hline Mild increase into some fibers & - & - & - & - & - & + & - & - & - & - \\
\hline Deficiency fibers dispersed & + & - & - & - & - & - & - & - & - & - \\
\hline \multicolumn{11}{|l|}{ PAS } \\
\hline Deficiency fibers dispersed & +++ & + & ++ & - & - & - & - & +++ & - & - \\
\hline \multicolumn{11}{|l|}{ Succinic dehydrogenase } \\
\hline Subsarcolemal accumulation & - & - & - & - & +++ & + & + & - & - & - \\
\hline Focal deficiency into fibers & + & ++ & - & - & - & - & - & - & ++ & - \\
\hline \multicolumn{11}{|l|}{ Cytochrome c oxidase } \\
\hline Subsarcolemal accumulation & - & - & - & - & ++ & + & + & - & - & - \\
\hline Focal deficiency into fibers & + & ++ & - & - & - & - & - & - & ++ & - \\
\hline \multicolumn{11}{|l|}{ Deaminase adenilate } \\
\hline Deficiency fibers dispersed & - & - & - & - & - & ++ & - & - & - & + \\
\hline \multicolumn{11}{|l|}{ Myophosphorylase } \\
\hline Deficiency fibers dispersed & +++ & - & + & + & - & + & - & +++ & - & - \\
\hline
\end{tabular}

*: time-period between the initial symptoms and death; F: female; M: male; Q: quadriceps; G: gastrocnemius; P: major pectoral; HE: hematoxylin-eosin; PAS: periodic acid Schiff; -: absent; +: present, rare or mild; ++: occasional or moderate; +++: frequent or severe. 


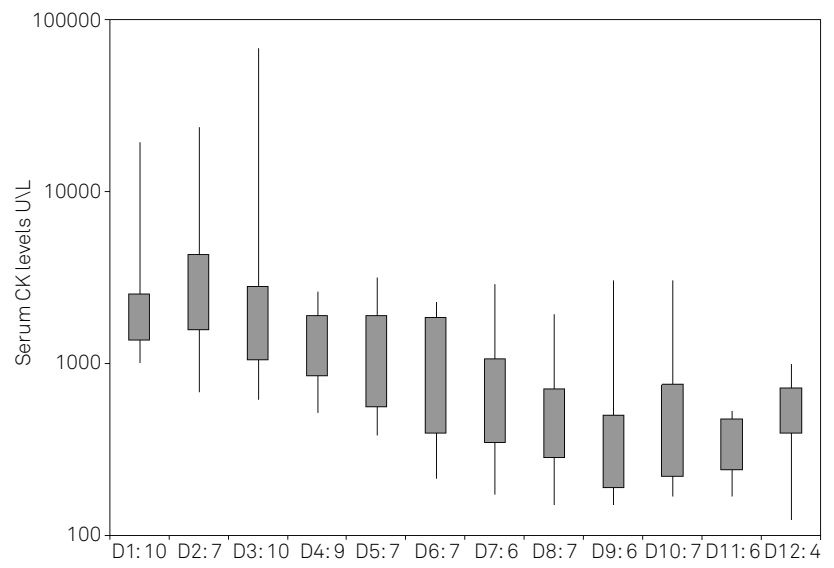

Days at ICU and number of patients

Fig 1. Serum creatine kinase (CK) levels from intensive care unit (ICU) admission to death in ten critically ill patients with 2009 influenza A (H1N1) infections. The boxes represent the interquartile range, which contains $50 \%$ of individual patient's CK level. The lines indicate the highest and lowest CK values. stains), but those alterations could be consistent with metabolic dysfunction. These findings were in line with the hypothesis of systemic metabolic dysfunction related to multiple organ dysfunction syndrome.

Although our critically ill patients had elevated CK levels, they exhibited few histological/histochemical abnormalities in their muscle biopsy samples. We believe that additional studies on muscle biopsies with an emphasis on the direct viral invasion mechanism and biochemistry findings (mitochondrial and cytokines) are needed to determine the pathogenesis associated with influenza H1N1 in muscles.

\section{ACKNOWLEDGEMENTS}

We are grateful to the Epidemiology Service and Intensive Care Unit at the Hospital de Clínicas da Universidade Federal do Paraná for their collaboration in this study.

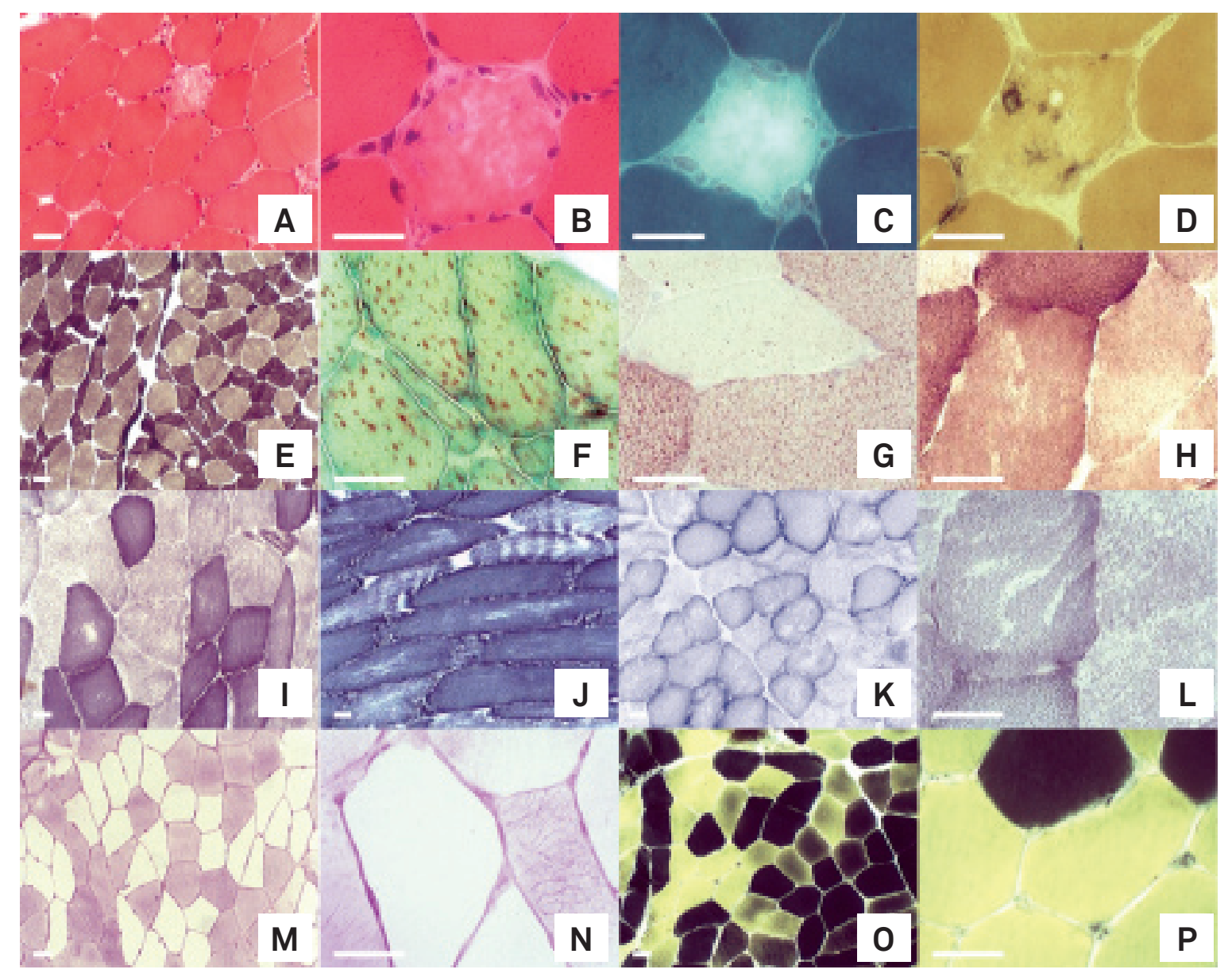

Fig 2. Histological and histochemical abnormalities in muscle biopsy - (A/B) fibers with simple necrosis (case 2; hematoxylineosin); (C) fibers with simple necrosis (case 8; modified Gomori trichrome); (D) fibers with simple necrosis (case 2; alkaline phosphatase); (E) selective atrophy of the type 2 fibers (case 3; ATPase pH 9.4); (F) focal increased into fibers (case 3; acid phosphatase); (G) fiber with lipid deficiency (case 1; Oil red O); (H) mild focal COX deficiency into fibers (case 1; Cytochrome c oxidase); (I/J) focal NADH failure into fibers (case 9; NADH - tetrazolium reductase); (K) mild subsarcolemmal SDH accumulation (case 6; Succinic dehydrogenase); (L) focal SDH deficiency into fibers (case 1; Succinic dehydrogenase); (M) dispersed fibers with glycogen deficiency (case 8; periodic acid Schiff); (N) dispersed fibers with glycogen deficiency (case 1; periodic acid Schiff); and (O/P) dispersed fibers with deficiency activity of myophosphorylase (case 8; Myophosphorylase). Bar) $50 \mu \mathrm{m}$. 


\section{References}

1. Perez-Padilla R, de la Rosa-Zamboni D, de Leon SP, et al. Pneumonia and respiratory failure from swine-origin influenza A (H1N1) in Mexico. N Engl J Med 2009;361:680-689.

2. Chowell G, Bertozzi SM, Colchero MA, et al. Severe respiratory disease concurrent with the circulation of H1N1 Influenza. N Engl J Med 2009;361:674-679.

3. Kumar A, Zarychanski R, Pinto R, et al. Critically ill patients with 2009 influenza A (H1N1) infection in Canada. JAMA 2009;302:1872-1879.
Domíngues-CheritG, LapinskySE,MaciasAE,etal.Criticallyill patients with 2009 influenza A (H1N1) in Mexico. JAMA 2009;302:1880-1887.

5. Werneck LC. The value of muscle biopsy in neurology: a study of 290 biopsies. Rev Bras Clin Ter 1981;10(Suppl):S2-S24.

6. Agyeman P, Duppenthaler A, Heininger U, Aebi C. Influenza-associated myositis in children. Infection 2004;32:199-203.

7. Kuiken T, Taubenberger J. Pathology of human influenza revisited. Vaccine 2008;25:D59-D66. 